DOI: $10.2478 / \mathrm{v} 10129-011-0014-1$

A. Comeau ${ }^{1}$, F. Langevin ${ }^{1}$, V.R. Caetano ${ }^{2}$, S. Haber $^{3}$, M.E. Savard ${ }^{4}$, H. Voldeng ${ }^{4}$,

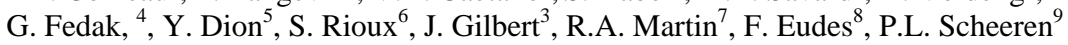

${ }^{1}$ CRDSGC, Agriculture and Agri-Food Canada, Québec City, QC, Canada G1V 2J3; ${ }^{2}$ EMBRAPA CLIMA TEMPERADO, CP 403, Pelotas, RS, 96001-970, Brazil; ${ }^{3}$ CRC, Agriculture and AgriFood Canada, Winnipeg, MB, Canada R3T 2M9; ${ }^{4}$ ECORC, Agriculture and Agri-Food Canada, Ottawa, ON, Canada K1A 0C6; ${ }^{5}$ EEROM, Saint-Mathieu-de-Beloeil, QC, Canada J3G 2E0; ${ }^{6}$ CÉROM, Québec City, QC, Canada G1P 3W8; ${ }^{7}$ Agriculture and Agri-Food Canada, Charlottetown, PEI, Canada C1A 4N6; ${ }^{8}$ Agriculture and Agri-Food Canada, Charlottetown, PEI, Canada C1A 4N6; ${ }^{9}$ EMBRAPA

Trigo, CP 451, 99001-970, Passo Fundo, RS. Brazil

\title{
A DIFFERENT PATH TO THE SUMMIT OF FUSARIUM HEAD BLIGHT RESISTANCE IN WHEAT: DEVELOPING GERMPLASM WITH A SYSTEMIC APPROACH
}

\begin{abstract}
In pursuing FHB resistance in wheat, 30 years of conventional breeding efforts in Eastern Canada have brought some progress. Substantial investment and the application in recent years of marker-assisted selection have to date, however, failed to produce agronomic lines that resist FHB as well as Sumai 3. We present here an alternative path, described as the systemic approach. Rather than seeking to introgress specific putative resistance genes, it subjects target germplasm to regimes of repeated cycles of multiple, interacting (biotic and abiotic) stresses in which desirable traits - not always adequately expressed in parental lines - are identified and selected. How can such a seemingly counterintuitive process work? The systemic approach views desired resistance as arising from the interactions of complex regulation mechanisms mediating how a host responds when a pathogen attacks. These constituents of resistance should thus not always be understood simply as discrete Mendelian units. In repeated rounds of selection, the systemic approach captures those rare individuals that embody optimal interactions of traits, and advances them as founders of lines that resist FHB more effectively than if selection focused on FHB alone. In Quebec, we have chosen to select wheat populations under combined pressure from barley yellow dwarf virus (BYDV) infection and FHB. Resistance to FHB and tolerance of BYDV are quantitative traits that interact. BYD increases both the direct losses from FHB and the production of mycotoxins. Selection under virus pressure, therefore, helps identify those individuals which express FHB resistance more effectively. Moreover, the correlates of virus tolerance (physiological efficiency, generalized stress tolerance and yield) point to those plants with better root traits, ability to produce biomass and yield stability. Together with numerous secondary criteria, such selection eliminates all but a few 'winners' in each round. Seen from a systemic perspective, the difficulty of identifying good progeny among
\end{abstract}

Communicated by Edward Arseniuk 
descendants of crosses with Sumai 3 does not surprise. Deleterious linkages, pleiotropy and epistasis will usually combine in far from optimal expressions of the assembled genetic information. The systemic approach, by contrast, identifies in repeated cycles increasingly optimized expressions of genes, allowing all potential sources of resistance to be explored. Thus resistant lines can readily be derived from the crosses of susceptible parents, an objective rarely sought in conventional, focused approaches. Moreover, wheat plants respond to the systemic approach's powerful stresses with enhanced epigenetic variation, raw material from which broader ranges of heritable traits can be selected. Germplasm that expresses a full range of attractive traits while resisting FHB as effectively as Sumai 3 can now be shown to be much more abundant than previously imagined. Perhaps this promise will entice more wheat workers to try a systemic approach.

Key words: barley yellow dwarf virus (BYDV), biotic and abiotic stresses, Fusarium Head Blighy (FHB), genotypes, resistance, traits interaction

\section{INTRODUCTION}

Although research has been conducted on Fusarium Head Blight (FHB) in Canada for nearly a century, only since the 1980 s has it captured the attention of the general public, first in Quebec and then in Ontario and Manitoba. What changed? Modern production methods using contemporary cultivars more strongly predispose crops to the disease, and a warmer climate may now also enhance overall disease severity. Organic farmers, accepting lower yields to forswear using herbicides and chemical fertilizers, by contrast, generally experience less FHB. Whatever the choice of production system, we need cultivars that can resist the disease far more effectively. Genetic resistance has long been available in such parents as Nobeoka Bouzu, Nyu Bay, Sumai 3 and many others but combining such resistance with yield and quality has proved an elusive goal.

Resistance to FHB is not a discrete trait that is expressed in isolation from developmental and morphological traits that affect agronomic success. As Couture (1982) demonstrated, and Hilton et al. (1999) confirmed, tall genotypes accumulate less Fusarium, a phenomenon subsequently shown to be strongly linked to resistance (Voss et al. 2008, Löffler et al. 2009, Mao et al. 2010). While we have made incremental progress in improving disease resistance in shorter genotypes (Comeau and Langevin, unpubl.), it remains easier to select for resistance in taller plant types. Tallness, unfortunately, is linked to lodging and therefore the potential for severe yield losses exists (Cruz et al. 2000, 2001). Many FHB resistance genes turn out to be linked with genes for increased shattering, another agronomic deficiency (Zhang and Mergoum 2009). Finally, what appears to be FHB resistance in many lines may actually be an artifact of their late maturity and greater likelihood of thus escaping infection.

In this context it should not surprise that the success of marker-assisted selection (MAS) at introgressing FHB resistance into agronomically superior lines has been decidedly modest. 


\section{THE SYSTEMIC WAY}

Our work after 1997 was inspired by discussions with EMBRAPA scientists who had observed the vast complexity of interactions that exist in wheat between traits, and between traits and environments. Those discussions involved multiple academic disciplines, as for example root traits and efficient mineral absorption also appeared related to disease resistance (Comeau et al. 2005, Datnoff et al. 2007). A large number of traits and environmental factors could influence Fusarium resistance (Comeau et al. 2003). For example, cultivar registration trial data showed many genotypes adapted to dry areas had exceptionally high sensitivity to the disease. In our crossing and selection work, those were very poor parents for FHB goals.

We rapidly became convinced that a simple approach of selecting for one trait (Fusarium resistance) would lead nowhere. Without duplicating the breeder's work, the pathologist had to develop broader understanding about the breeding and selection processes, and understand that heredity is not just a matter of dealing with Mendelian traits. Genetic research has found many exceptions to what was seen as dogma 15 years ago; stress can induce useful de novo variation of various kinds (Haber et al. 2010, Comeau et al. 2010). Moreover, all traits compete in their expression for photosynthate that is in limited supply (Geiger and Servaites 1991), thus, the expression of all genes is inter-related (Comeau et al. 2010) and evolution has come up with very subtle and complex regulatory mechanisms to deal with a variable and unpredictable environment. In fact, as expressed so clearly by Robinson (2009), "a special aspect of quantitative variables is that they must all be increased simultaneously"; and one must never forget FHB resistance is quantitative.

The application of those new ideas thus began in Brazil, while Canadians became part of discussions with EMBRAPA about new genetic approaches and developed parallel approaches based on a common philosophy. The approach was named systemic as it was understood one should not focus on a single key trait (like Fusarium); it was essential to develop a grasp on the whole genetic system of the plant, considering its interactions with a variable environment, and not neglecting the needs of farmers and customers.

\section{METHODS}

A pivotal decision was to use barley yellow dwarf virus (BYDV) in order to select for biomass potential while increasing the Fusarium damage. This virus affects root growth and root system efficiency; genotypes that tolerate the virus tend to have high biomass and better mineral uptake (Comeau and Haber 2002). Moreover, the same virus increases Fusarium damage in 
wheat (Liu and Buchenauer 2005). Thus the virus could in theory facilitate the discovery of lines that combine yield with FHB resistance. As in theory a faster overall progress might be possible through selection with all diseases combined, attempts at combining BYDV with FHB were made first on $\mathrm{F}_{2} \mathrm{~S}$ in 2002. In practice, the mix of those two diseases proved quite deadly. But it became our standard basic approach, and other stresses and factors listed in Table 1 were gradually added, to be used in any given selection cycle. Stress-free plots were seldom grown in Quebec.

Table 1

List of stresses and selection factors used most commonly in the systemic approach in Quebec, beginning at the $F_{1}$ level and pursued over 2 to 6 generations.

\begin{tabular}{|c|c|c|}
\hline Step & $\begin{array}{l}\text { Zadoks } \\
\text { scale }\end{array}$ & Stress or selection factor \\
\hline A & 00 & Seed appearance, gluten \\
\hline $\mathrm{B}$ & 01 & $\begin{array}{l}\text { (opt.) Planting in poor quality soil (hard, deficient in minerals, etc); planting in weedy } \\
\text { soils, with zero use of pesticides and fertilizer }\end{array}$ \\
\hline $\mathrm{C}$ & $11-13$ & (opt.) flooding resistance \\
\hline $\mathrm{D}$ & 14 & BYDV (predisposes to FHB) \\
\hline $\mathrm{E}$ & $13-25$ & stem and leaf rust inoculum \\
\hline $\mathrm{F}$ & $13-25$ & mildew inoculum \\
\hline G & $33-40$ & corn spawn (Fusarium inoculum) \\
\hline $\mathrm{H}$ & $59-70$ & spray of Fusarium inoculum, 3 days/week \\
\hline $\mathbf{J}$ & $95-99$ & plant morphology; shattering; height; biomass; maturity range \\
\hline
\end{tabular}

\section{RESULTS AND DISCUSSION}

Since there is no obvious reason to avoid selecting as early as the $\mathrm{F}_{1}$ generation, the double disease stress was then tried on $9000 \mathrm{~F}_{1} \mathrm{~s}$ in 2003 . Almost all were destroyed or eliminated using stresses and selection factors A, D, E, G, and H (Table 1).

Only one cross had clean good-looking plants (QG22.24/Alsen//SS Blomidon/Alsen, a $F_{1} / F_{1}$ cross). It was grown two cycles indoors with mildew selection stress and then submitted in later generations to various protocols, always including at least selection factors A, D, G, H, K, J (Table 1) in field trials, and sometimes factors B, C, E, F in field or indoors trials.

Out of $9000 \mathrm{~F}_{1}$ plants, only one cross had performed satisfactorily, and one single plant from the best complex cross $\left(\mathrm{F}_{1} / \mathrm{F}_{1}\right)$ was more resistant than its 12 sisters with identical pedigree. One could safely conclude that multiple disease resistance in a good plant type was a very rare event. 
During the selection process that followed, the multi-resistant AB143 segregated for resistance to all diseases, and was selected accordingly. In 2006, at the $\mathrm{F}_{6}$ level, based on visual symptoms, its Fusarium resistance was distributed in a bimodal manner, with one group of that had about Alsen's resistance, and the other group that had much better resistance. There were no intermediate lines. DON measurement by the Ottawa ELISA method were obtained for all lines from the low-symptom group (Fig. 1). In this group about half of the lines had less DON than Sumai 3.

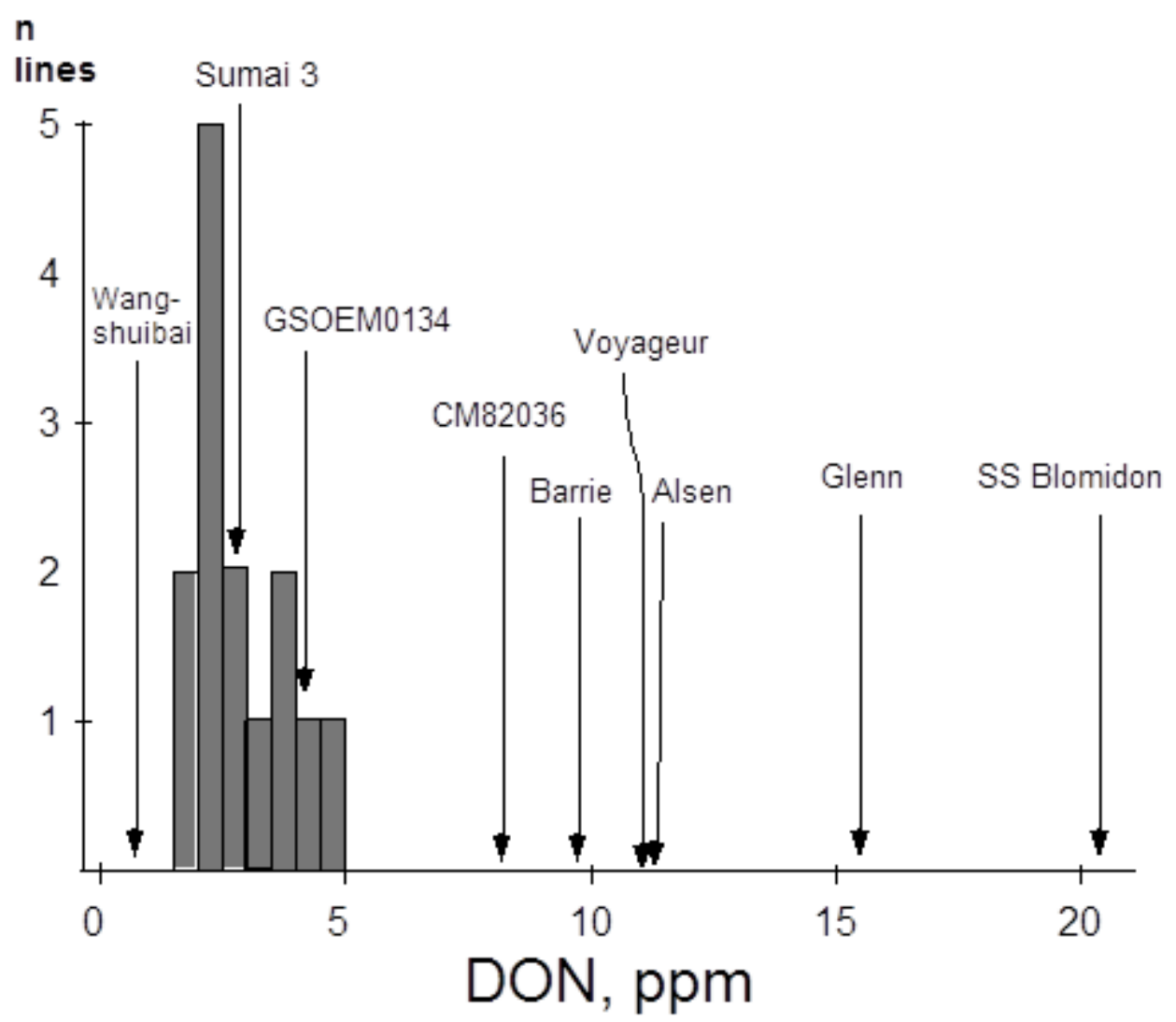

Fig. 1. Distribution of frequency for the DON content in the $F_{6}$ generation, for all of the low-symptom lines derived from the best $\mathrm{AB} 143 \mathrm{~F}_{1}$ plant chosen in 2003 (gray histogram). The DON is also shown for Alsen and SS Blomidon, which are part of the parents of AB143. The DON level of the $3^{\text {rd }}$ parent (QG22.24) in other trials is usually above that of Barrie (data not shown).

This trend persisted over years, and after four selection cycles in the field, all AB143-origin lines were within the range of Sumai 3 for DON content. One unexpected finding was that for type II resistance, these lines were clearly somewhat inferior to Sumai 3 . Rachis and spikes of the best AB143 selections were damaged by point infections, despite the fact that the lines had QTLs showing type II should have been rather good (Comeau 
et al. 2010). Nevertheless, they were mostly endowed with excellent type I resistance, and despite showing rachis symptoms of Fusarium, the grain quality remained very good, and the DON was low.

After 2004, progenies from AB143 became the backbone of the local germplasm development program. We observed that crossing a MS wheat with an AB143 derivative can yield about one line with Sumai 3 level resistance out of 200 or 300; the advantage over Sumai 3 is that the selections are quite free from serious agronomic defects, and can be good yielders. Plant height and maturity remain aspects that we try to improve. During the last decade, scientists from private and public institutions came out with cultivars that had valuable FHB resistance levels; those include Kingsey, Duo, AW625, Nass and others in the MR to MS category. Crossing AB143 derivatives with these MR or MS cultivars sometimes led to slightly higher frequencies of resistant progenies; however, recurrent selection materials in which both parents contained genes from AB143 behaved best, in terms of yielding more resistant lines. The Lethbridge haploid derived line GSOEM-0134 became one of the favorite parents, as a source of strong type II resistance, in the hope of improving over AB143. Derivatives combining high resistance of both type I and II have been found.

It is interesting to compare our approach with the conventional, pervasive wisdom of doing very few crosses and selfing for many generations before serious selection and decision-making (Baker 1984, Witcombe and Virk 2010). It almost appears that by restricting the use of diversity, geneticists have come to grossly underestimate the need for a wide diversity of genes. Additionally, without proper verification, delaying selection until advanced generations has often been chosen as the best approach, despite the fact that there was neither evidence nor theoretical reasons leading to expect major drawbacks from earlier selection (Bernardo 2003). Consider also that the AB143 cross is resistant to FHB, but it does not contain any parent that is resistant (Fig 1). Studies of the markers present in the most resistant AB143 derived lines showed the presence of resistance genes obtained from susceptible and moderately susceptible parents (Comeau et al. 2010). There must be quite a number of genes necessary for maximum resistance; other studies confirm the complexity of type I resistance mechanisms in wheat, and a cumulative effects of many minor genes (Mesterhazy 2005).

At this point in time the products of the systemic approach are becoming noteworthy for their exceptional specific weight. We can now obtain from systemic-derived germplasm grown in FHB inoculated trials a specific weight that is better than the specific weight of popular cultivars grown in farmers fields. Examples are shown in Table 2. None of the systemic-derived entries in the advanced FHB trials done in 2009 in Quebec had a specific weight lower than that of check AC Barrie. It became clear that FHB is one of the principal determinants of specific weight in both natural conditions and artificially inoculated FHB trials in Quebec. Therefore, if severe and repeated Fusarium inoculation is performed, specific weight can be a low-cost indicator of FHB resistance and overall disease resistance. 
Table 2

Data on advanced systemic lines entered in the FHB resistance trial labeled as 09CRF in Quebec; additional data from neighboring plots not inoculated but naturally infected by Fusarium in 2009. Some lines were replicated, but newer germplasm was not

\begin{tabular}{|c|c|c|c|c|c|c|}
\hline \multirow[b]{2}{*}{ Genotype } & \multirow[b]{2}{*}{ Reps } & \multicolumn{3}{|c|}{ 09CRF trial, FHB-inoculated } & \multicolumn{2}{|c|}{ Natural infection } \\
\hline & & $\begin{array}{c}\text { Specific } \\
\text { weight }\end{array}$ & $\mathrm{FDK}^{\mathrm{a}}$ & $\begin{array}{l}\text { Yield [kg/ } \\
\text { ha] }\end{array}$ & $\begin{array}{c}\text { Specific } \\
\text { weight }\end{array}$ & $\mathrm{FDK}^{\mathrm{a}}$ \\
\hline $\mathrm{AB}-505(\mathrm{SP}) \mathrm{B} 21 \mathrm{~A}^{\mathrm{b}}$ & 1 & 83.4 & 2.2 & 4307 & - & - \\
\hline $\mathrm{AB}-505(\mathrm{SP}) \mathrm{B} 21 \mathrm{~A}^{\mathrm{b}}$ & 1 & 82.5 & 1.2 & 4136 & - & - \\
\hline ERA13R4 ${ }^{\mathrm{b}}$ & 1 & 82.2 & 9.0 & 3850 & - & - \\
\hline FL94R $1^{c}$ & 2 & 82.2 & 6.2 & 2967 & - & - \\
\hline ERA6R $1^{\mathrm{b}}$ & 1 & 81.5 & 9.3 & 4661 & - & - \\
\hline ERA13R $3^{b}$ & 1 & 81.4 & 7.0 & 3957 & - & - \\
\hline ERA73R2 ${ }^{\mathrm{d}}$ & 1 & 81.0 & 4.0 & 4166 & - & - \\
\hline ERA13 ${ }^{\mathrm{b}}$ & 1 & 80.5 & 4.5 & 3836 & - & - \\
\hline $\mathrm{AB}-505(\mathrm{SP}) \mathrm{B} 21 \mathrm{~A}^{\mathrm{b}}$ & 1 & 80.4 & 1.7 & 3771 & - & - \\
\hline PL259.H $1^{\mathrm{b}}$ & 1 & 80.0 & 9.2 & 3447 & - & - \\
\hline ERA6R $4^{\mathrm{b}}$ & 1 & 79.9 & 13.3 & 4169 & - & - \\
\hline ERA8R4 ${ }^{\mathrm{b}}$ & 1 & 79.3 & 7.3 & 3526 & - & - \\
\hline$A B-370 . A 4 B 6^{d}$ & 1 & 78.3 & 2.2 & 4262 & - & - \\
\hline Nyu Bay (R check) & 1 & 77.7 & 7.7 & 2211 & - & - \\
\hline PL249.N1 & 3 & 76.4 & 10.2 & 3785 & - & - \\
\hline Sumai 3 (R check) & 4 & 77.2 & 6.8 & 2536 & - & - \\
\hline Aso Zairai (from Japan) & 1 & 76.0 & 2.0 & 2431 & - & - \\
\hline W984-8767 (new cultivar) & 1 & 75.4 & 13.2 & 3189 & 80.3 & 0.4 \\
\hline Duo (MR check) & 4 & 74.8 & 16.9 & 2168 & 82.5 & 0.5 \\
\hline BRS177 (MR check) & 1 & 74.3 & 18.5 & 1991 & 81.2 & 0.8 \\
\hline AC Barrie (MS check) & 4 & 73.4 & 28.7 & 1642 & - & - \\
\hline Glenn (MS check) & 1 & 72.0 & 24.0 & 1706 & 81.5 & 1.0 \\
\hline Hoffman (MS check) & 2 & 70.9 & 21.2 & 2153 & - & - \\
\hline FHB37 (MS check) & 1 & 70.8 & 25.0 & 1735 & - & - \\
\hline Waskada (MS check) & 1 & 70.6 & 35.0 & 1933 & - & - \\
\hline SS Blomidon (S check) & 3 & 68.7 & 23.3 & 1636 & 74.2 & 1.5 \\
\hline FL94R9 $^{\mathrm{c}}$ (R check) & 1 & - & - & - & 85.3 & 0.2 \\
\hline Helios (MS check) & 1 & - & - & - & 77.8 & 1.7 \\
\hline Lillian (S check) & 1 & - & - & - & 72.8 & 8.3 \\
\hline
\end{tabular}

${ }^{a}$ FDK is the percent visibly Fusarium damaged kernels.

${ }^{\mathrm{b}}$ Germplasm obtained from the systemic approach and derived from crosses to AB143.

${ }^{\mathrm{c}}$ Germplasm obtained from the systemic approach and derived directly from AB 143 itself .

${ }^{\mathrm{d}}$ Germplasm obtained from the systemic approach and not derived from AB143.

The products of the systemic approach are recognized for low DON. Data on this matter was obtained during the selection process for the cross AB143. Almost half of the low-symptom selections had DON levels that were lower than that of Sumai 3, and all of them were markedly better than 
the current popular cultivar AC Barrie (Fig. 1). This trend of very low DON was maintained in more recent selections from systemic germplasm.

Agronomic valuation is done by many collaborators at many test sites. Those collaborators will obtain more complete and reliable data in multisite trials in 2010, but most of the systemic germplasm is still in the early phases of evaluation (generally at one single site). The best germplasm from conventional approaches was compared to one single line from the systemic approach, at four sites in Eastern Canada. This showed that both the conventional approach and the systemic approach can generate germplasm with resistance not far from that of Sumai 3; however, based on the mean of 4 sites, the systemic derived line FL62R1 had 30\% more yield and yet lodged less. Lodging score was 1.0 for FL62R1 vs 3.7 for the highest yielding FHB R from conventional approach.

Attempts to simplify selection systems were not perceived as desirable, since there were always plenty of survivors in complex-stress selection systems after 2006; leaf spot resistance is pursued, and new stresses like smuts, bunt and ergot are envisioned as possible additions. Thus, it was decided to continue to use a very large number of crosses, most of them being $\mathrm{F}_{1} / \mathrm{F}_{1}$ so as to maximize the genetic diversity within crosses and introduce new resistance factors. Furthermore, in following years, those new crosses were submitted to various combinations of stress and selection factors listed in Table 1. Our recent research goals are now tackling new aspects like gluten quality, because we feel the critical part of the needed progress against FHB has been achieved.

Stress itself must now be considered as a generator many kinds of de novo genetic variability. This needs further study, but it happens at measurable rates. A virus stress for example generates useful variants for resistance to many diseases, including FHB, even from pure lines or doubled haploid lines (Haber et al. 2010), leading to readily usable variation.

\section{CONCLUSION}

In the systemic approach, we combine the impact of many diseases, gaining a lot from the fact that BYDV increases Fusarium pressure. This very destructive approach is compensated by making a large number of crosses per year. Systemic lines with high resistance can be obtained in large numbers, and at each generation, genes for resistance to diseases of secondary importance can be introduced or re-introduced gradually.

If consideration is given to obtaining results, the systemic approach should become popular, as it delivers more results at rather low cost. In fact, it gets results no other method can obtain. 


\section{ACKNOWLEDGEMENTS}

We thank Drs Tom Fetch and Brent McCallum for supplying rust isolates and parental lines. Thanks also to the Fédération des Producteurs de Cultures Commerciales for supporting a significant part of the research dedicated since 2003 to developing the systemic approach.

\section{REFERENCES}

Baker, RJ 1984. Quantitative genetic principles of plant breeding. pp. 147-176. in: Gustafson JP, ed. Gene manipulation in plant improvement I. Plenum Press, NY, USA.

Bernardo R. 2003. On the effectiveness of early generation selection in self-pollinated crops. Crop Science 43 : 1558-1560.

Comeau A, Langevin F, Eudes F. 2003. Mechanisms of resistance and tolerance to FHB. Pp 88-105. Proc. 3rd Can. Workshop FHB. www.cwfhb.org/programs/3_CWFHB_2003_Winnipeg.pdf

Comeau A, Haber S. 2002. Breeding for BYDV tolerance in wheat as a basis for a multiple stress tolerance strategy. Pp 82-92. in: Henry M, McNab A (eds) Barley yellow dwarf disease, recent advances and future strategies. CIMMYT, Mexico.

Comeau A, Langevin F, Lévesque M. 2005. La santé des racines : le monde de la complexité. [Root health: a world of complexity] Phytoprotection $86: 43-52$ (Fr.).

Couture L. 1982. Receptivity of spring cereals to contamination of grains in the inflorescence by Fusarium spp. Can. J. Plant Sci. 62 : 29-34.

Comeau A, Caetano VR, Haber S, Langevin F, Lévesque M, Gilbert J. 2010. Systemic heuristic approaches guide the interaction of enhanced genetic diversity and complex stresses to generate better wheat germplasm faster and at lower cost. Chap. 19 in: Kovalchuk I, Kovalchuk O. (eds). Genetics and epigenetics of transgenerational response to stress. Nova Sc Publ., Hauppage, NY.

Cruz PJ, Carvalho FIF, Caetano VR et al. 2000. Efeito do acamamento induzido em trigo. [Effects of provoked lodging in wheat] Revista Brasileira de Agrociência, v.6, n.2,p.112-114. (Port.).

Cruz PJ, de Carvalho FIF, Caetano VR, Silva SA, Kurek AJ, Barbieri RL. 2001. Traits associated with lodging resistance in bread wheat. Cienc. Rural, vol.31, no.4, p.563-568. ISSN 0103-8478.

Datnoff LE, Elmer WH, Huber DM (eds). 2007. Mineral nutrition and plant disease. Am. Phytopathol. Soc. Press. St-Paul, MN, USA. 278 pp. ISBN 978-0-89054-346-7

Geiger D, Servaites J. 1991. Carbon allocation and response to stress. in: Mooney H, Winner W, Pell E, Chu E. (eds). Response of plant to multiple stresses. Acad Press. 103-127.

Haber S, Gilbert, J, Seifers, DL, Comeau, A. 2010. Epigenetics serves genetics: Fusarium Head Blight (FHB) resistance in elite wheat germplasm. In: The Americas J Plant Sci Biotech. (Global Science Books Ltd, UK). (in press).

Hilton AJ, Jenkinson P, Hollins TW, Parry DW. 1999. Relationship between cultivar height and severity of Fusarium ear blight in wheat. Plant Pathol. 48:202-208.

LiuY, Buchenauer H. 2005. Interactions between barley yellow dwarf virus and Fusarium spp. affecting development of Fusarium head blight of wheat. Eur. J. Plant Pathol. 113: 283-295.

Löffler M, Schön CC, Miedaner T. 2009. Revealing the genetic architecture of FHB resistance in hexaploid wheat (Triticum aestivum L.) by QTL meta-analysis. Mol. Breed. 23: 473-488. DOI 10.1007/s11032008-9250-y.

Mao SL, Wei YM, Cao W, Lan XJ, Yu M, Chen ZM, Chen GY, Zheng LM. 2010. Confirmation of the relationship between plant height and Fusarium head blight resistance in wheat (Triticum aestivum L.) by QTL meta-analysis. Euphytica DOI 10.1007/s10681-010-0128-9.

Mesterhazy A, Buerstmayr H, Tóth B, Lehoczki-Krsjak Sz, Szabó-Hevér Á, Lemmens M. 2007. An improved strategy for breeding FHB-resistant wheat must include type 1 resistance. Pp 51-66. Proc. 5th Can. Workshop on FHB.

Robinson R. 2009. Breeding for quantitative variables. part 2. Breeding for durable resistance to crop pests and diseases. pp. 367-390 in: Ceccarelli S, Guiamarães EP, Weltzien E. Plant breeding and farmer participation. FAO, Rome, Italy. 671 pp. ISBN 978-92-5-106382-8. (see especially p. 383)

Voss HH, Holzapfel J, Hartl L, Korzun V, Rabenstein F, Ebmeyer E, Coester H, Kempf H, Miedaner T. 2008. Effect of the Rht-D1 dwarfing locus on Fusarium head blight rating in three segregating populations of winter wheat. Plant Breed. 127: 333-339. 
Witcombe JR, Virk DS. 2009. Methodologies for generating variability. Part 2: Selection of parents and crossing strategies. pp. 129-138 in: Ceccarelli S, Guiamares EP, Weltzien E. (eds). Plant breeding and farmer participation. FAO, Rome, Italie.

Zhang G, Mergoum M. 2009. Molecular mapping of kernel shattering and its association with Fusarium head blight resistance in a Sumai 3 derived population. Theor Appl Genet. 115 : 757-766. 